Article

\title{
Design and Analysis of Dual-Rotor Modular-Stator Hybrid-Excited Axial-Flux Permanent Magnet Vernier Machine
}

\author{
Lun Jia $^{1}$, Mingyao Lin ${ }^{1, *}$, Keman Lin $^{2}$, Wei Le ${ }^{1}$ and Anchen Yang ${ }^{1}$ \\ 1 School of Electrical Engineering, Southeast University, Nanjing 210096, China; lunjia@seu.edu.cn (L.J.); \\ 230189220@seu.edu.cn (W.L.); yac1994@seu.edu.cn (A.Y.) \\ 2 College of Energy and Electrical Engineering, Hohai University, Nanjing 210098, China; \\ linkeman@hhu.edu.cn \\ * Correspondence: mylin@seu.edu.cn
}

check for updates

Citation: Jia, L.; Lin, M.; Lin, K.; Le, W.; Yang, A. Design and Analysis of Dual-Rotor Modular-Stator Hybrid-Excited Axial-Flux Permanent Magnet Vernier Machine. Energies 2022, 15, 1458. https:// doi.org/10.3390/en15041458

Academic Editors: Federico Barrero and Ryszard Palka

Received: 20 January 2022

Accepted: 14 February 2022

Published: 16 February 2022

Publisher's Note: MDPI stays neutral with regard to jurisdictional claims in published maps and institutional affiliations.

Copyright: (C) 2022 by the authors. Licensee MDPI, Basel, Switzerland. This article is an open access article distributed under the terms and conditions of the Creative Commons Attribution (CC BY) license (https:// creativecommons.org/licenses/by/ $4.0 /)$

\begin{abstract}
This paper proposes a new structure of the dual-rotor hybrid-excited axial-flux permanent magnet vernier machine (DR-HEAFPMVM) with the modular stator and the consequent-pole PM (CPM) rotor for low-speed, high torque density applications such as in-wheel electric vehicles. The tooth-wound non-overlapping armature windings and direct current (DC) excitation windings are, respectively, arranged in stator main-teeth and split-teeth to obtain the modulated and adjustable air-gap flux densities, resulting in high torque density and outstanding flux-weakening capability. First, the design considerations, operation principles, and air-gap flux density distributions of the proposed machine are elaborated based on the air-gap permeance function. Then, the influence of the pole ratios (PRs) and the DC excitation currents on the main electromagnetic performances of the DR-HEAFPMVM, such as the flux-weakening capability and back-electromotive force (back-EMF), on-load electromagnetic torque, loss distribution, and efficiencies, is investigated using the 3-D finite-element method (FEM). Results verify the feasibility of the flux adjustment of the DC excitation windings equipped in the split-tooth, and the design with a pole ratio of $8 / 1$ tends to have higher torque density, higher machine efficiency, and considerable flux-weakening capability compared with the other two PRs.
\end{abstract}

Keywords: dual-rotor; modular-stator; hybrid-excited; axial-flux permanent magnet vernier machine; 3-D finite-element method

\section{Introduction}

Low-speed, high-torque direct-drive machines have broad application prospects in wind turbines, in-wheel drives, ship propulsions, and so on [1,2]. The regular electric drive system of a high-speed machine with reduction gear leads to the disadvantages of complexity, poor reliability, high maintenance cost, and low system efficiency. With the merits of high torque density enabled by the magnetic gearing effect, the magnetically geared (MG) machine is getting more and more attention [3-6].

The magnetic field modulation (MFM) principle was first proposed by Prof. Howe [7] and consists of a high-speed rotor and a low-speed rotor, sandwiched by a flux-modulationpoles (FMPs) ring. Through the MFM effects of FMPs, constant electromagnetic torque can be achieved with a different number of stator and rotor poles. Hence, the pole ratio (PR), defined as the number ratio of rotor to stator pole pairs, can realize specific transmission. The MG machine is achieved by integrating the magnetic gears with electric machines, substituting the rotating magnetic field of the outer of the PM rotors with the rotating magnetic field generated by the armature windings [8,9]. Hence, the MG machine has a separated FMP ring and a PM rotor with two air-gap layers, resulting in high complexity and low reliability. One of the solutions is to fix the FMPs to the stator poles with either split-tooth or non-split teeth $[6,8,10]$, forming the PM vernier machine (PMVM). 
In recent years, some improved topologies have been proposed to address the demerits of magnetic leakage and low power factor of PMVMs, such as dual-stator spoke-array rotor, dual-PM both on stator and rotor, and consequent-pole PM (CPM) [11-14]. However, similar to the conventional PM machine, PMVM still suffers from the difficulty of adjusting the air-gap flux density [15]. Meanwhile, in the comparative study of PMVM and the 2010 Toyota Prius IPM machine [16], it was found that PMVM features limitations for adjustable-speed applications due to the narrow constant power speed range (CPSR). The negative d-axis current can be injected for the flux-weakening, but it increases the capacity of the inverter and raises the risk of irreversible demagnetization of the PMs. Hence, the hybrid-excited machine has been developed as an effective and practical solution that combines the synergies of high-torque density of the PM machine with the flexible flux regulation of the wound field machine $[17,18]$. The air-gap flux density can operate as a flux-weakening or flux-enhancing condition by controlling the current direction of the direct current (DC) excitation winding. Furthermore, regular PMVMs with distribution windings tend to suffer long end turns, which takes up space that offsets part of the torque density. In $[19,20]$, PMVMs with tooth-wound and core-wound non-overlapping windings are proposed, respectively, which reduce the end turns effectively.

At present, most research on PMVM focuses on radial-flux machines. With the inherit features of plane air-gap and compactness, the axial-flux PM (AFPM) machines have become strong competitors to the advanced electric drive. Among the common AFPM machine topologies, the dual-rotor (DR) structure has been shown to have a high power and torque density [21-24]. With the combination of the DR-AFPM machine and VM, a DR core-wound AFPMVM is proposed in [25], which proves the advantages of the 24-slot 22-pole with a PR of 11/1 in torque density. In [26], the CPM is applied to the DR corewound PMVM to improve PM utilization and cost, which is due to the replacement of PM poles with iron poles as well as the reduced leakage flux. Moreover, the DC excitation windings are introduced in the stator main-tooth to adjust the amplitude of the armature winding flux linkage [27], in which the CPM is applied to modulate the stationary DC field due to the interactions with the salient rotor structure. However, the space in the armature winding slots that the DC windings would occupy results in a decrease in the torque density of the machine. Hence, the introduced DC excitation winding increases the harmonics of air-gap flux density and increases the complexity of machine design and analysis. Research on the DR-AFPMVMs with hybrid excitation windings to regulate the flux density is still limited.

This paper presents a novel topology of dual-rotor hybrid-excited AFPMVM (DRHEAFPMVM) with a modular stator and tooth-wound non-overlapping windings to improve the flux-weakening capability and torque density. The design consideration and modulated principle of the air-gap flux density distributions of the proposed machines are derived first with three different PRs. Then, the flux-weakening principle and capability introduced by the DC excitation windings are studied. Finally, the typical electromagnetic performances both in no-load and load conditions are conducted and compared using the 3-D finite-element method (FEM) to investigate the optimal PR of the proposed machines under different DC excitation currents.

\section{Machine Structure and Operating Principle}

\subsection{Structure of DR-HEAFPMVM}

The exploded diagram of the proposed DR-HEAFPMVM is depicted in Figure 1 . The machine is derived from a conventional DR-AFPM machine, with two outer rotors and one stator sandwiched in between. Thereinto, the stator is divided into twelve modules, each of which consists of a main-tooth and three split-teeth at each end. Additionally, the split-tooth is used to accommodate the flux modulation effect to achieve a higher torque density. Accordingly, the tooth-wound non-overlapping concentrated windings accommodate each main tooth as two-layer armature windings. In order to regulate the air-gap flux density, the magnetic flux derived by the DC excitation windings wounded 
on each intermediate split-tooth is superimposed on the main flux path. Furthermore, the CPMs on the DRs are circumferentially aligned, forming the Torus NS configuration, which is also named as the yokeless and segmented armature (YASA) configuration [21]. Different from the conventional Torus NN configuration with a stator yoke, which splits the reverse magnetic fluxes of the rotors on both sides through the stator yoke to form an even symmetrical magnetic circuit, the absence of a stator yoke takes the merit of the odd symmetrical flux that shortens the length of the main flux path, reduces the weight of the stator cores, and increases the torque density [21,28]. Due to the split-tooth, the original magnetic flux generated by CPMs is modulated to the high-speed magnetic flux, which has the same number of pole pairs as the armature windings, to realize the electromechanical energy conversion.

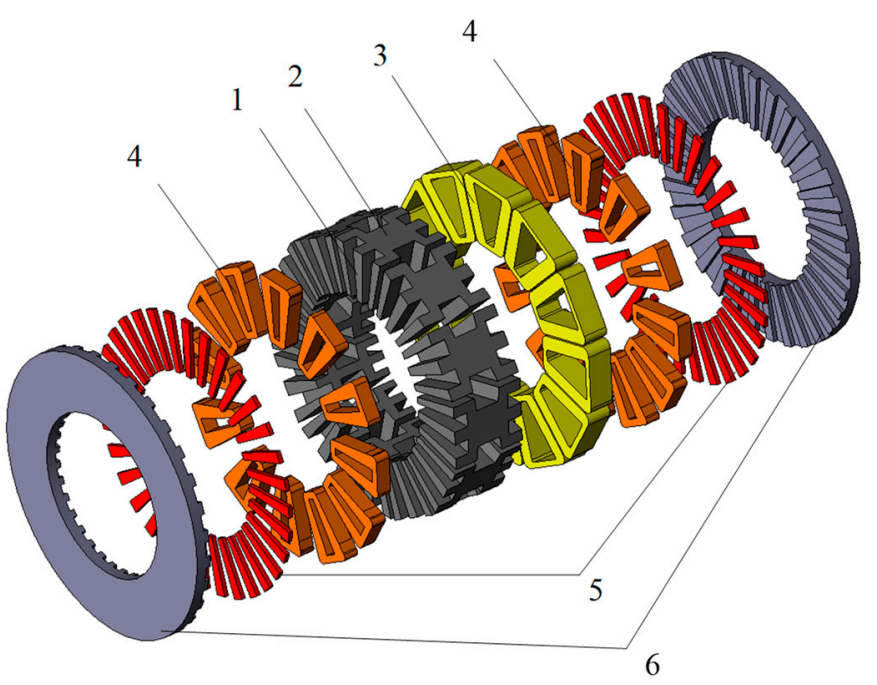

Figure 1. Exploded view of the proposed DR-HEAFPMVM. 1-Stator split-tooth, 2-stator maintooth, 3-armature windings, 4-DC excitation windings, 5-PMs, and 6-rotor back iron.

\subsection{Operational Principle}

Assuming that the magnetic permeability of the cores is infinite and the PM has linear magnetic properties, the machine's static characteristics can be calculated at the average diameter; as shown in Figure 2, the Fourier series of the magnetomotive force (MMF) $F_{P M}$ developed by CPMs can be expressed as

$$
F_{P M}\left(\theta_{s}, t\right)=\sum_{i=1}^{\infty} F_{P M g i} \cos \left[i p_{r}\left(\theta+\omega_{r} t\right)\right]
$$

where $\theta$ is the mechanical angle on the stator, and $p_{r}$ and $\alpha_{p}$ are the number of PM pole pairs and the pole arc ratio to pole pith, respectively. $\omega_{r}$ is the electrical angular velocity. $F_{P M g}$ is the amplitude of the $i$-th order harmonic, and $i$ is a positive integer.

With the employment of sector-shaped slots formed by the split-teeth, the air-gap permeability is constant with the variation of radius. As shown in the Figure 2, the air-gap permeance coefficient function of the stator can be expressed as the superimposition of the permeance coefficient functions introduced by the stator modular and the split-tooth

$$
\Lambda(\theta)=\sum_{j=0}^{\infty} \Lambda_{s j} \cos \left(j Z_{s} \theta\right)+\sum_{j=0}^{\infty} \Lambda_{m j} \cos \left(j p_{m} \theta\right)
$$

where $j$ is either 0 or a positive integer, $Z_{S}$ is the number of the stator modular, and $p_{m}$ is the number of split-teeth. Hence, the modulated open-circuit air-gap flux density in the axial direction is expressed as 


$$
\begin{aligned}
& B_{g m}(\theta, t)=F_{P M} \Lambda \\
& =\frac{1}{2} \sum_{j=0}^{\infty} \sum_{i=1}^{\infty} F_{P M g i} \Lambda_{s j} \cos \left[i p_{r} \omega_{r} t+\left(i p_{r}+j Z_{s}\right) \theta\right]+\frac{1}{2} \sum_{j=0}^{\infty} \sum_{i=1}^{\infty} F_{P M g i} \Lambda_{s j} \cos \left[i p_{r} \omega_{r} t+\left(i p_{r}-j Z_{s}\right) \theta\right] \\
& +\frac{1}{2} \sum_{j=0}^{\infty} \sum_{i=1}^{\infty} F_{P M g i} \Lambda_{m j} \cos \left[i p_{r} \omega_{r} t+\left(i p_{r}+j p_{m}\right) \theta\right]+\frac{1}{2} \sum_{j=0}^{\infty} \sum_{i=1}^{\infty} F_{P M g i} \Lambda_{m j} \cos \left[i p_{r} \omega_{r} t+\left(i p_{r}-j p_{m}\right) \theta\right]
\end{aligned}
$$

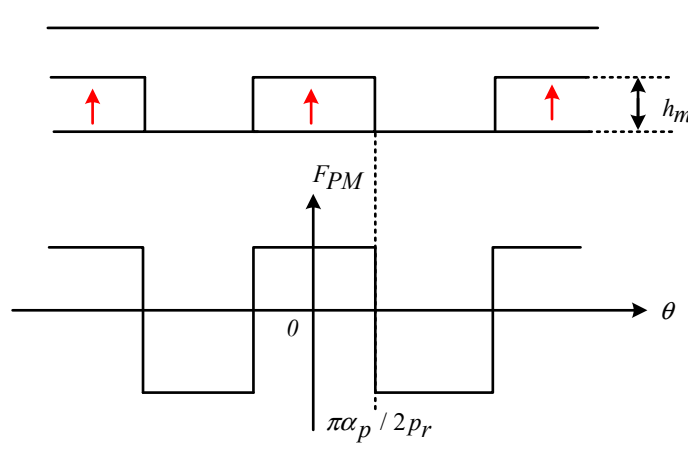

(a)

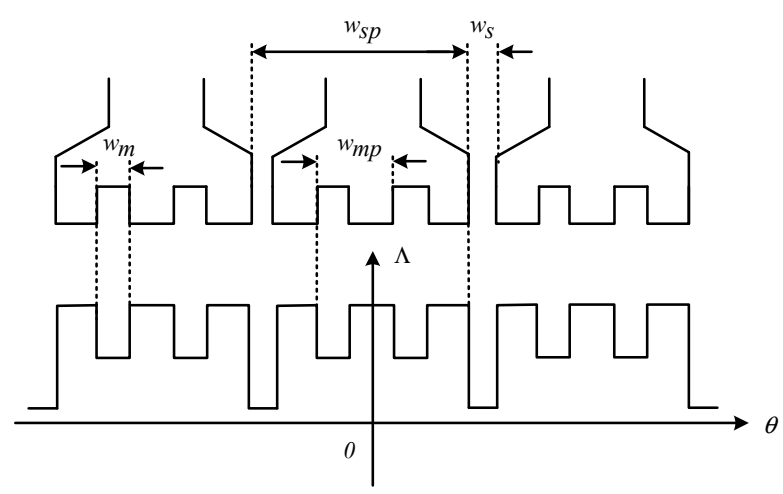

(b)

Figure 2. Air-gap MMF and permeance function distributions in the proposed machine. (a) The MMF distribution generated by the CPMs. (b) $\Lambda$ accounts for the stator slotting.

From (3), the attributed harmonics can be classified into three types as (1) original harmonics of order $i p_{r}$ with the rotation speed of $i p_{r} \omega_{r},(2)$ modulated harmonics of order $\left|i p_{r} \pm j Z_{s}\right|$ with the rotation speed of $i p_{r} \omega_{r} /\left(i p_{r} \pm j Z_{s}\right)$, and (3) modulated harmonics of order $\left|i p_{r} \pm j p_{m}\right|$ with the rotation speed of $i p_{r} \omega_{r} /\left(i p_{r} \pm j p_{m}\right)$. When only the constant and the first-order components of MMF $F_{P M}$ and permeance coefficient $\Lambda$ are considered, the $B_{g m}$ can be expressed as

$$
\begin{gathered}
B_{g m}(\theta, t) \approx F_{P M g 1} \Lambda_{s 0} \cos \left[p_{r}\left(\theta+\omega_{r} t\right)\right]+F_{P M g 1} \Lambda_{m 0} \cos \left[p_{r}\left(\theta+\omega_{r} t\right)\right] \\
+\frac{F_{P M g 1} \Lambda_{s 1}}{2} \cos \left[\left(p_{r} \pm Z_{s}\right) \theta+p_{r} \omega_{r} t\right]+\frac{F_{P M g 1} \Lambda_{m 1}}{2} \cos \left[\left(p_{r} \pm p_{m}\right) \theta+p_{r} \omega_{r} t\right]
\end{gathered}
$$

where the $F_{P M g 1}$ is derived by the function related to the PM thickness $h_{m}$ and residual magnetism $B_{r}$. Additionally, the $\Lambda_{0}$ and $\Lambda_{1}$ can be expressed by the conformal mapping method [29] as follows:

$$
\begin{gathered}
F_{P M g 1}=\frac{\pi}{4} \frac{B_{r}}{\mu_{0} \mu_{r}} h_{m} \sin \left(\frac{\pi}{2} \alpha_{p}\right) \\
\Lambda_{s 0}=\frac{\mu_{0}}{g^{\prime}}\left[1-1.6 \beta_{s} \frac{w_{s}}{w_{s p}}\right] \Lambda_{m 0}=\frac{\mu_{0}}{g^{\prime}}\left[1-1.6 \beta_{m} \frac{w_{m}}{w_{m p}}\right]
\end{gathered}
$$

$$
\begin{array}{r}
\Lambda_{s 1}=\frac{\mu_{0}}{g^{\prime}} \frac{2}{\pi} \beta\left\{\frac{0.78125}{0.78125-2\left[\frac{w_{s}}{w_{s p}}\right]^{2}}\right\} \sin \left[1.6 \pi \frac{w_{s}}{w_{s p}}\right] \Lambda_{m 1}=\frac{\mu_{0}}{g^{\prime}} \frac{2}{\pi} \beta\left\{\frac{0.78125}{0.78125-2\left[\frac{w_{m}}{w_{m p}}\right]^{2}}\right\} \sin \left[1.6 \pi \frac{w_{m}}{w_{m p}}\right] \\
g^{\prime}=g+\frac{h_{m} \alpha_{p}}{2 \mu_{r}} \\
\beta_{s}=\frac{1}{2}\left\{1-\left[1+\left(\frac{w_{s}}{2 g^{\prime}}\right)^{2}\right]^{-\frac{1}{2}}\right\} \beta_{m}=\frac{1}{2}\left\{1-\left[1+\left(\frac{w_{m}}{2 g^{\prime}}\right)^{2}\right\}^{-\frac{1}{2}}\right\}
\end{array}
$$

where $\mu_{0}$ and $\mu_{r}$ are the permeability of vacuum and the relative permeability of PMs, respectively. $w_{m}$ and $w_{m p}$ are the widths of the slot opening of the split-teeth and of the stator split-teeth pitch, respectively. $w_{s}$ and $w_{s p}$ are the widths of the slot opening of the 
stator modular and of the stator modular pitch, respectively. From Equations (5)-(8), the slot openings of the stator modular and the split-teeth, the air-gap length, and the PM thickness affect the constant term and fundamental harmonics of the air-gap permeance, thereby affecting the harmonic amplitude of the air gap flux density, which will be further investigated in the following section.

It can be seen from (3) that the magnetic flux modulation effect can obtain the flux components of both $p_{m}+p_{r}$ and $p_{m}-p_{r}$. Then, neglecting the curvature effect of AFPMVM, the expression of maximum steady torque $T$ can be obtained as in [1] by differentiating the magnetic field energy with respect to mechanical angle

$$
T=\frac{3 \sqrt{2}}{2 \pi}\left(D_{o}-D_{i}\right) \psi p_{r} k_{d 1} k_{p 1} N_{s} I\left(\left(\Lambda_{s 0}+\Lambda_{m 0}\right) F_{P M g 1} \mp \frac{\left(\Lambda_{s 1}+\Lambda_{m 1}\right) F_{P M g 1} p_{r}}{2 p_{s}}\right)
$$

where ' - ' is applied when $p_{r}=p_{m}-p_{\mathrm{s}}$, and ' + ' is applied when $p_{r}=p_{m}+p_{s}$. Additionally, $p_{S}$ is the number of stator pole pairs; $\psi$ is the flux linkage; $k_{d 1}$ and $k_{p 1}$ are the winding distribution and pitch factor, respectively; $N_{S}$ is the series turns per phase; and $I$ is the armature phase current. Obviously, with the selection of $p_{r}=p_{m}-p_{\mathrm{s}}$ in (10), the higher torque can be obtained.

\section{Electromagnetic Analysis and Comparison}

The influence of the PRs, namely, 8/1, 17/1, and 35/1, on the main performances of the proposed machine is analyzed and compared in this section using the 3-D FEM transient solution with software Ansys Maxwell, including the open-circuit air-gap flux density, flux linkage, flux-weakening capability, back-electromotive force (back-EMF), onload electromagnetic torque, and losses. The half model of the proposed machines is constructed with the 668,659 3-D tetrahedron meshes to reduce computational time, as shown in Figure 3. The Neumann boundary and the symmetry boundary are assigned to the outside faces and the cross-section of the machine region, respectively. It is assumed that the current densities of the armature windings and DC excitation windings are uniform on the cross-section of the respective conductors. The machine models participating in the comparison basically share the identical parameters in Table 1 and the same length-based mesh operation to make a reasonable comparison.

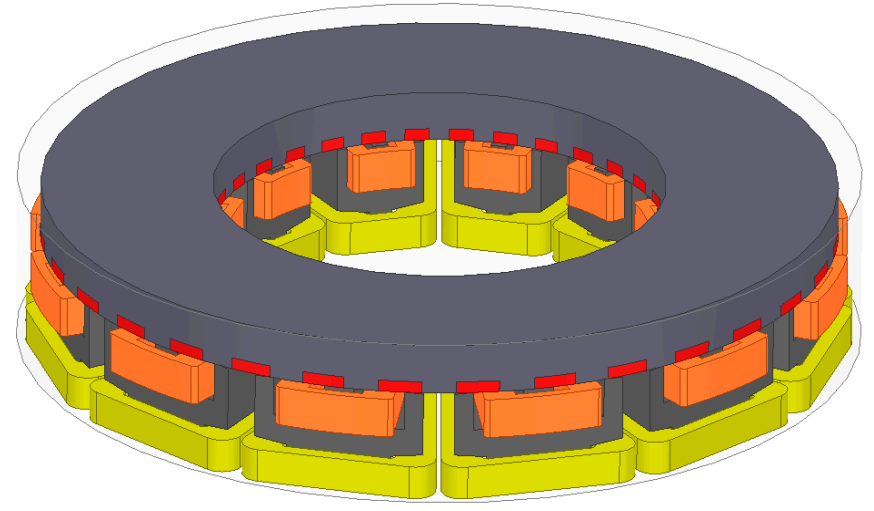

Figure 3. 3-D FEM model of the proposed DR-HEAFPMVM.

\subsection{Open-Circuit Air-Gap Flux Density and Flux Linkage}

The open-circuit air-gap flux density waveforms and spectra under different PRs are shown in Figure 4 to validate the previously deducted attributes of modulated field harmonics. For example, for the machine with PR equal to $8 / 1$, apart from the original harmonic order of the 32th $\left(p_{r}\right)$ with significant amplitude, the modulated harmonic order includes the 4 th $\left(p_{r} \pm p_{m}\right), 8$ th $\left(2 p_{r} \pm 2 p_{m}\right), 16$ th $\left(4 p_{r} \pm 4 p_{m}\right)$, and 36th $\left(9 p_{r} \pm 9 p_{m}\right)$. It should be noted that there is a fixed quantitative relationship between $Z_{S}$ and $p_{m}$ in the proposed machine. The attribute harmonics can be rewritten as the different $i, j$ corresponding to the 
$p_{r}$ and $Z_{s}$. Similarly, when the PR is equal to $17 / 1$, the original harmonic order of 34 th $\left(p_{r}\right)$ is the main contribution of the air-gap flux amplitude. The modulated harmonics include the 2 th $\left(p_{r} \pm p_{m}\right), 10$ th $\left(5 p_{r} \pm 5 p_{m}\right), 14$ th $\left(7 p_{r} \pm 7 p_{m}\right)$, and 36th $\left(18 p_{r} \pm 18 p_{m}\right)$. Additionally, the $35 / 1$ PR machine takes the harmonic order of 35th $\left(p_{r}\right)$, as well as the 11th $\left(11 p_{r} \pm 11 p_{m}\right)$, 13th $\left(13 p_{r} \pm 13 p_{m}\right)$, and 36th $\left(36 p_{r} \pm 36 p_{m}\right)$. The $p_{r} \pm p_{m}$ harmonic order of three types of PR machines holds the highest amplitude besides the order of $p_{r}$, reaching $0.16 \mathrm{~T}, 0.13 \mathrm{~T}$, and $0.13 \mathrm{~T}$, respectively.

Table 1. Specifications of the proposed DR-HEAFPMVMs.

\begin{tabular}{cccc}
\hline Symbol & Items & Value & Unit \\
\hline$D_{o}$ & Outer diameter & 302 & $\mathrm{~mm}$ \\
$D_{i}$ & Inner diameter & 172 & $\mathrm{~mm}$ \\
$L_{S}$ & Stator core axial length & 80 & $\mathrm{~mm}$ \\
$L_{r}$ & Rotor core axial length & 15 & $\mathrm{~mm}$ \\
$g$ & Air-gap length & 1.3 & $\mathrm{~mm}$ \\
$Z_{S}$ & Number of stator modular & 12 & $\mathrm{rpm}$ \\
$n_{N}$ & Rated speed & 375 & $\mathrm{~mm}$ \\
$h_{m}$ & PM thickness & 4.5 & $\mathrm{~T}$ \\
$B_{r}$ & PM remanent flux density & 1.3 &
\end{tabular}
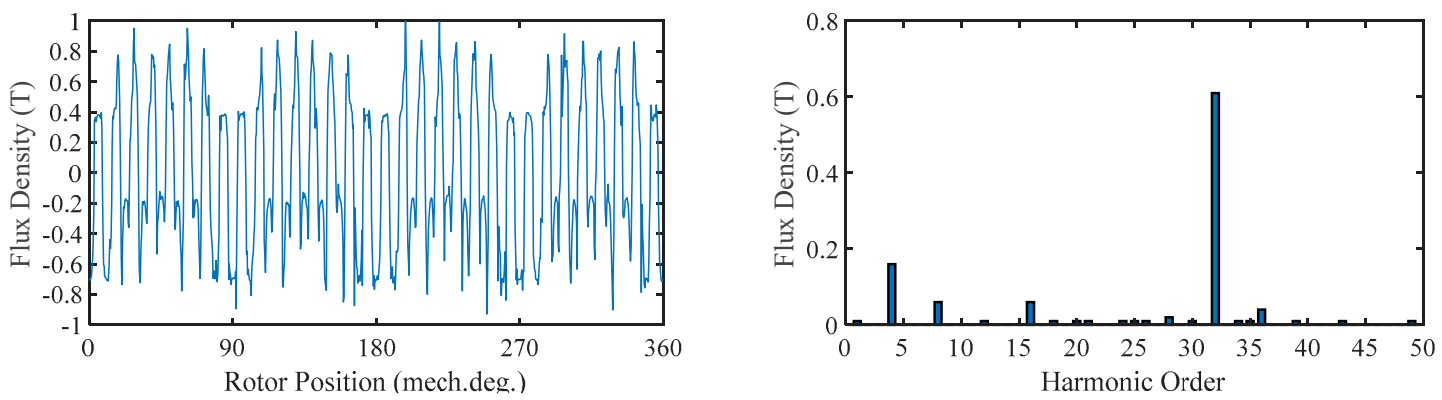

(a)
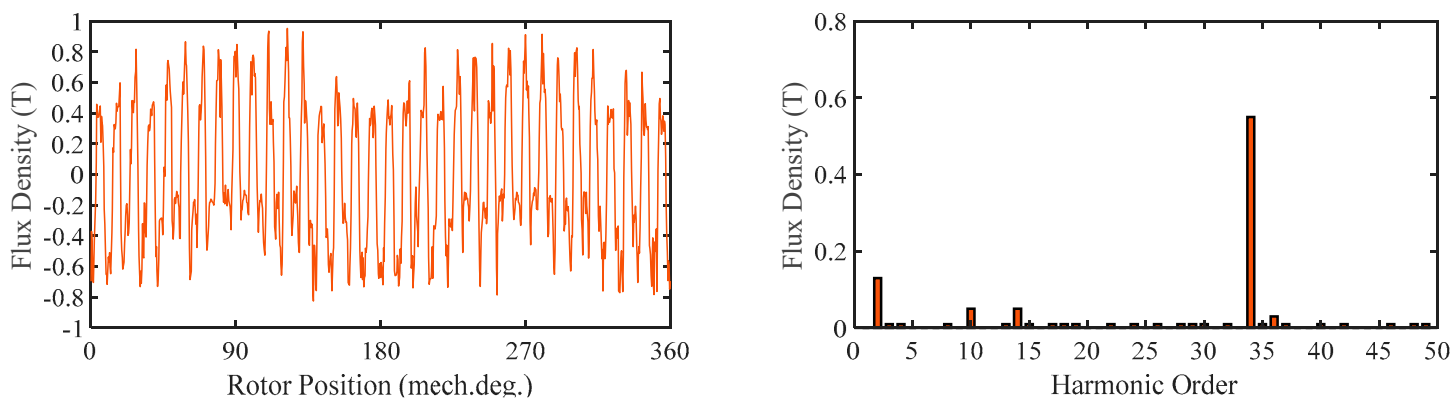

(b)
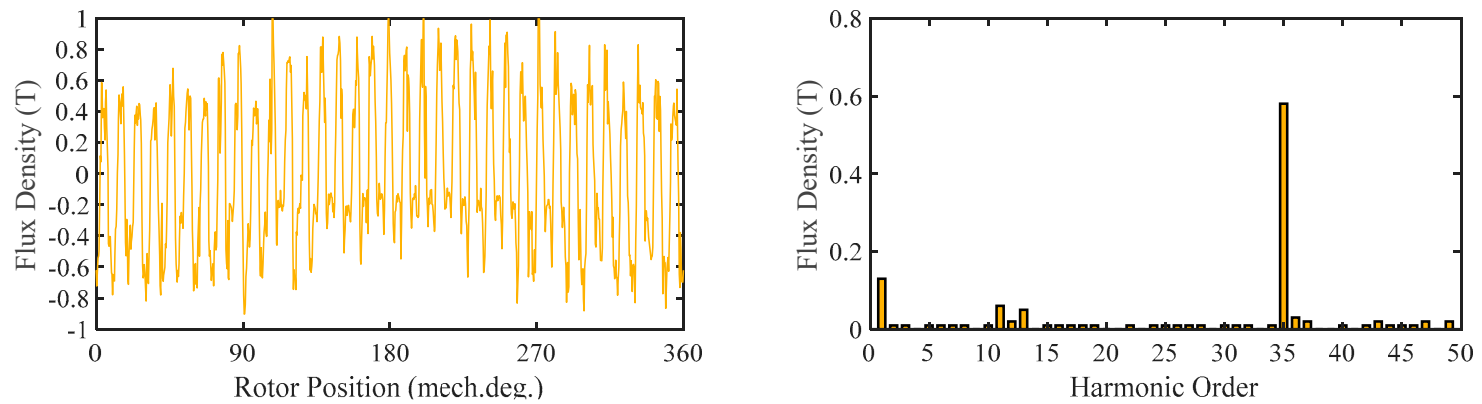

(c)

Figure 4. Open-circuit air-gap flux density waveforms and harmonic spectra with different PRs. (a) PR of 8/1. (b) PR of $17 / 1$. (c) PR of 35/1. 
Furthermore, Figure 5 shows the open-circuit armature phase flux linkage of three machines at rated speed. The amplitudes of the fundamental harmonics of the three machines are 4.01, 3.53, and 2.97, respectively. The machine with a PR of $8 / 1$ has larger second order phase flux linkage harmonics than its other two counterparts, while the machines with a PR of 17/1 and 35/1 witness larger third-order phase flux linkage harmonics than the PR of the $8 / 1$ machine. It should be noted that by star connection of the armature windings, the tripling line-to-line flux linkage and back-EMF harmonics can be eliminated.

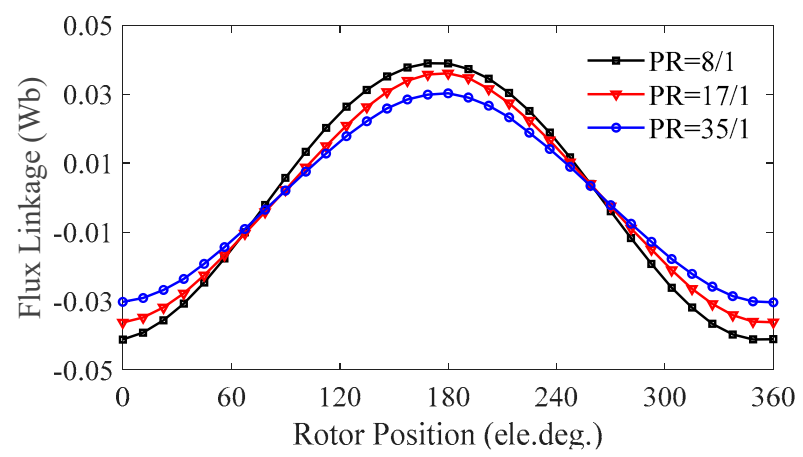

(a)

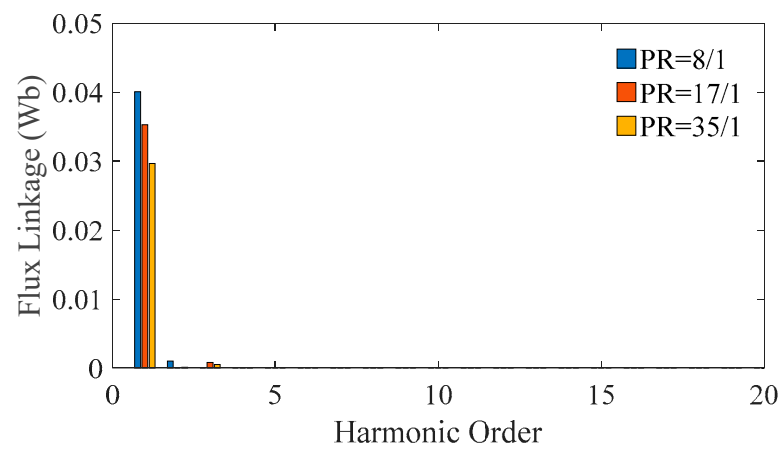

(b)

Figure 5. Open-circuit phase flux linkage waveforms and harmonic spectra with different PRs. (a) Flux linkage waveforms. (b) Harmonic spectra.

\subsection{Flux-Weakening Characteristic}

The FE predicted magnetic field vector distribution of DR-HEAFPMVM with a PR of $8 / 1$ as an example fed by a negative 10 ampere DC excitation current under zero armature windings current is shown in Figure 6. It can be seen that the PM excited field that should axially pass through the main stator teeth is bypassed by the DC excited field on the twoouter split-teeth, resulting in the reduction of the armature winding flux linkage. The larger the absolute value of the DC current, the more significant the short-circuiting effects are, and even the complete offset of the PM excited field as long as the saturation constraint is satisfied.

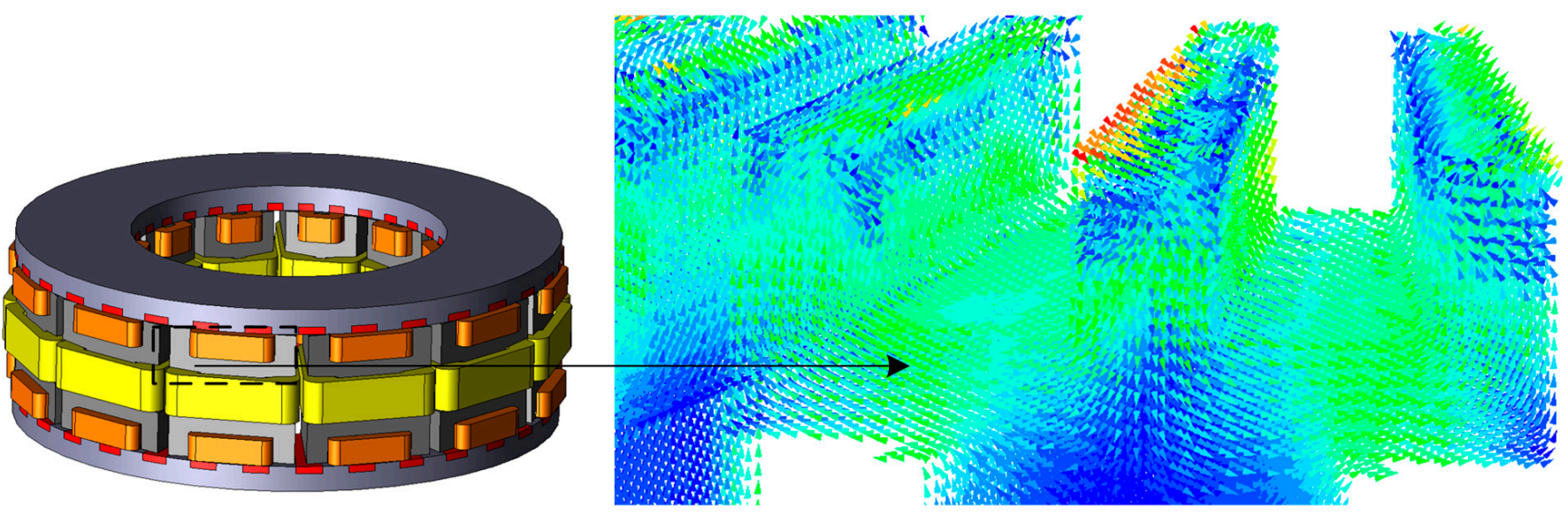

Figure 6. Flux-weakening path in stator split-teeth.

The flux-weakening rate $\xi$ is introduced to evaluate the flux-weakening capability, defined as

$$
\xi=\frac{\psi_{p m}-\psi_{f w}}{\psi_{p m}}
$$


where $\psi_{p m}$ is the amplitude of phase flux linkage derived by PM field and $\psi_{f w}$ is the amplitude of phase flux linkage under flux-weakening region. Figure 7 shows the changes of $\xi$ in response to the DC excitation current $I d c$ in three types of PRs. It can be seen that the good and similar linearity between $\xi$ and $I d c$ are achieved with three types of PRs. Among them, the machine with $17 / 1$ and 35/1 PRs displays better flux-weakening capability, with about $80 \%$ of the maximum flux-weakening rate. In comparison, the maximum fluxweakening rate of the machine with the $8 / 1 \mathrm{PR}$ is $77 \%$. However, the machine possesses a potentially lower power factor when $\xi$ is increased due to bypassing the main flux.

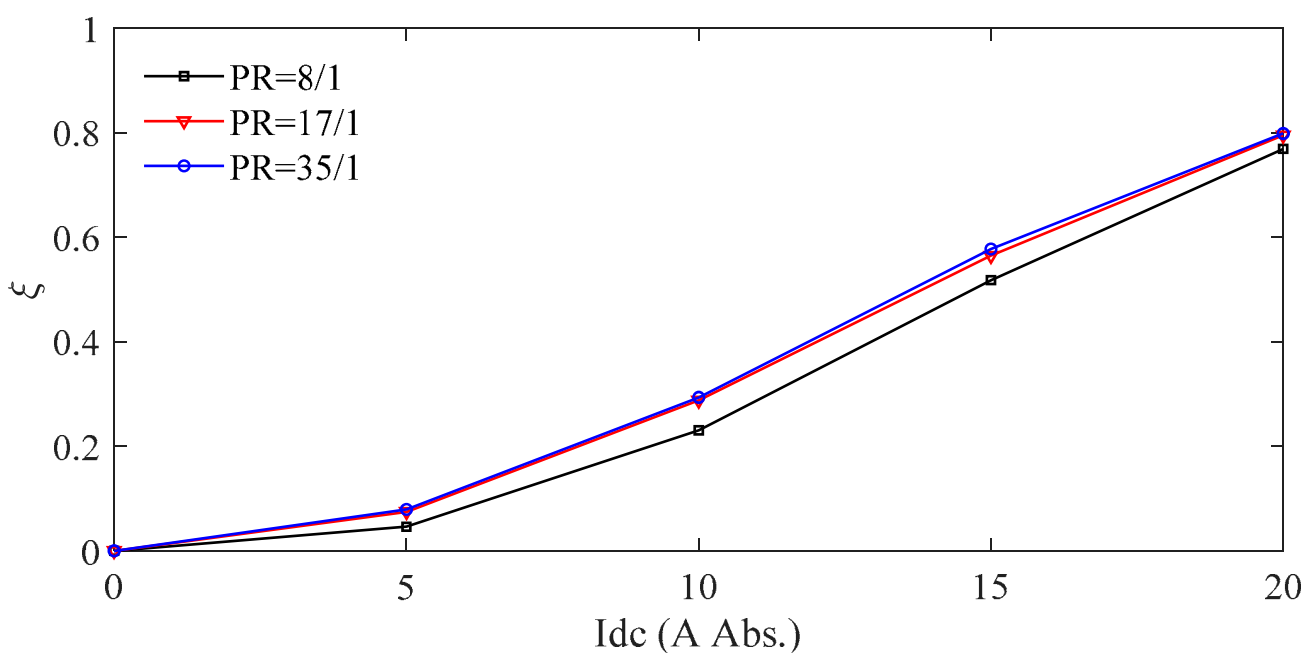

Figure 7. Evolution of $\xi$ as $I d c$ under different PRs.

The no-load back-EMF waveforms and harmonic spectra of the DR-HEAFPMVM with different PRs at the rated speed are illustrated in Figure 8. All the machines accommodate the sinusoidal back-EMFs with only PM excited fields. The fundamental amplitudes of the back-EMFs of three types of PR machines without DC excitations are 50.35, 47.03, and 40.75, respectively. The third-order harmonics occupied relatively higher amplitudes in the machines with the PR of $17 / 1$ and 35/1, resulting in total harmonic distortion (THD) of $7.03 \%$ and $5.23 \%$, respectively. Additionally, the second harmonic occurred in the machine with a PR of $8 / 1$, generating the a THD of $5.28 \%$, while the DC excitation current affects the phase flux linkage by short-circuiting the main flux, thereby affecting the THD of back EMFs, as shown in Table 2. Due to the saturation effect of iron materials, the back-EMF THD of the three types of machines tends to increase in the process of the deepening flux weakness. It is concluded that, compared with the other two PR configurations, the machine with the PR of $8 / 1$ takes the higher amplitude and lower THD of the back-EMF during the DC excitation current increase.

Table 2. The THD of the proposed DR-HEAFPMVMs with different PRs.

\begin{tabular}{cccccc}
\hline PR & $\boldsymbol{I} \boldsymbol{d} \boldsymbol{c}=\mathbf{0 A}$ & $\boldsymbol{I} \boldsymbol{d} \boldsymbol{c}=-\mathbf{5 A}$ & $\boldsymbol{I} \boldsymbol{d} \boldsymbol{c}=-\mathbf{1 0 A}$ & $\boldsymbol{I} \boldsymbol{d} \boldsymbol{c}=-\mathbf{1 5 A}$ & $\boldsymbol{I} \boldsymbol{d} \boldsymbol{c}=-\mathbf{2 0 A}$ \\
\hline $8 / 1$ & $5.28 \%$ & $2.85 \%$ & $1.89 \%$ & $1.50 \%$ & $9.11 \%$ \\
$17 / 1$ & $7.03 \%$ & $6.71 \%$ & $7.26 \%$ & $14.70 \%$ & $26.08 \%$ \\
$35 / 1$ & $5.23 \%$ & $4.85 \%$ & $4.51 \%$ & $9.20 \%$ & $17.16 \%$ \\
\hline
\end{tabular}



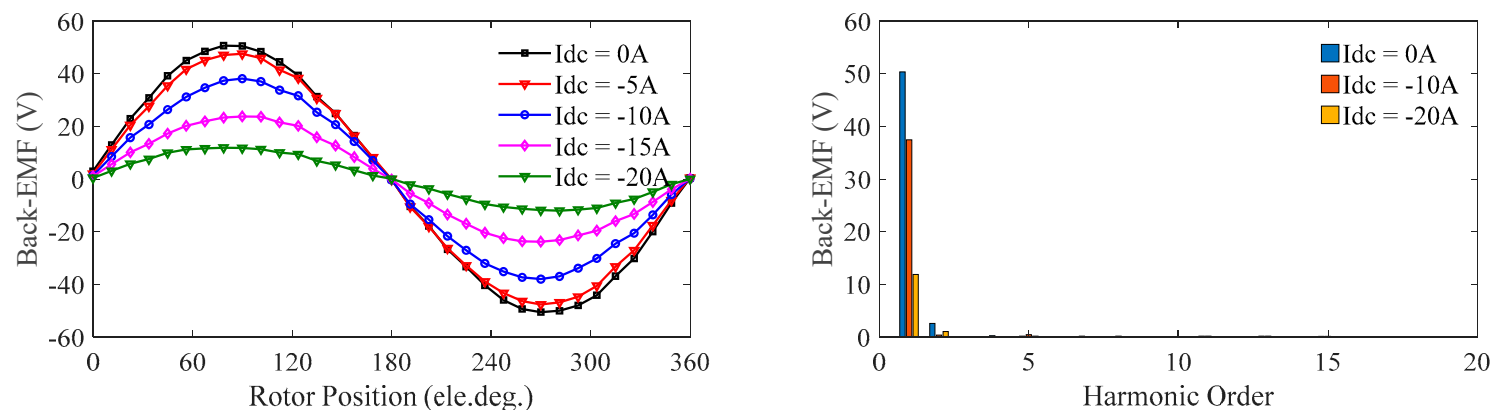

(a)
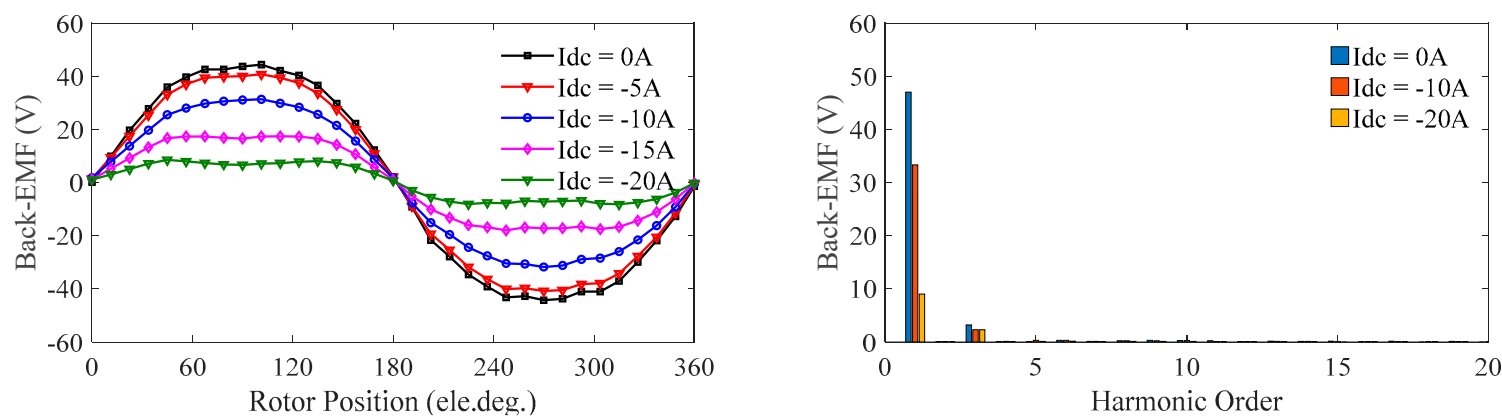

(b)
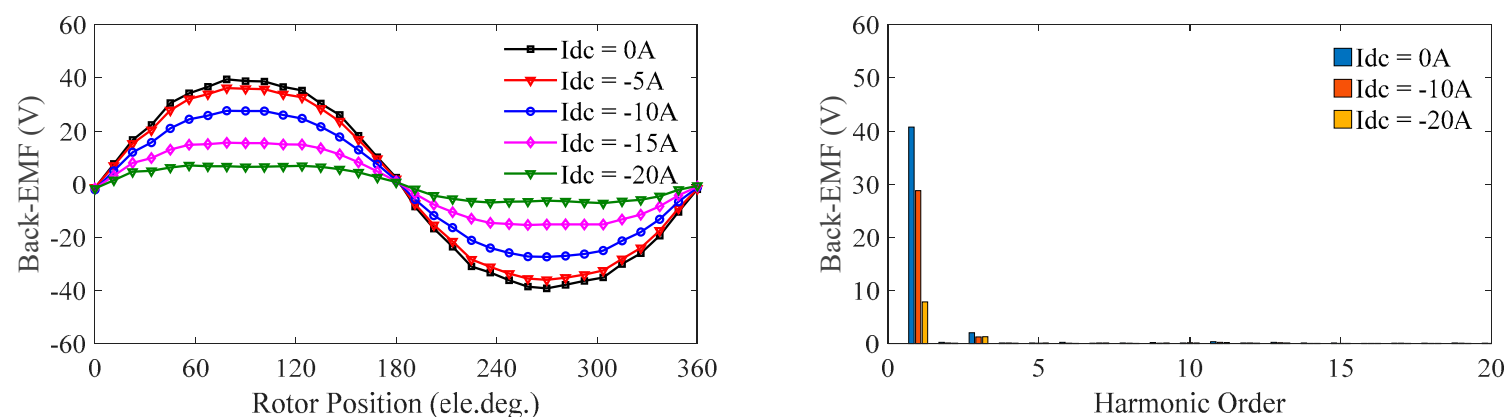

(c)

Figure 8. Back-EMF waveforms and harmonic spectra under variation of DC excitations with different PRs at rated speed. (a) PR of 8/1. (b) PR of 17/1. (c) PR of 35/1.

\subsection{Electromagnetic Torque}

The on-load electromagnetic torque waveforms under zero DC excitation current and flux-weakening region are shown in Figure $9 a-c$. The rated armature phase current is 120 amps. The machine with the PR of $8 / 1$ features the highest average output torque of $317 \mathrm{Nm}$ as well as the largest pulsating torque of $29 \mathrm{Nm}$ in the state of zero DC excitation current compared with its other two counterparts of $263 \mathrm{Nm}$ and $179 \mathrm{Nm}$. Hence, the maximum machine torque density can reach $39.3 \mathrm{kNm} / \mathrm{m}^{3}$. From the torque stability perspective, the machine with the PR of $35 / 1$ has the most stable torque waveform, with a $6.0 \%$ torque ripple in the state of zero DC excitation current, while the machines with PRs of $8 / 1$ and $17 / 1$ suffer from torque ripples of $9.1 \%$ and $6.7 \%$. The DC excitation current can effectively regulate the electromagnetic torque of three machines with less impact on the torque ripple. The maximum average torque regulation range of the three machines are $68 \%, 70 \%$ and $70 \%$, respectively. Regarding the contribution to the pulsating torque, the cogging torque of three machines is investigated further, as shown in Figure $9 \mathrm{~d}$. The amplitude of the cogging torque is closed rated to the least common multiple (LCM) of $p_{m}$ and $2 p_{r}$. The amplitude of cogging torque decreases with the increase of the PR because of the increase of LCM. Hence, the machine with PR of 35/1 has the minimum peak cogging torque compared with others. 


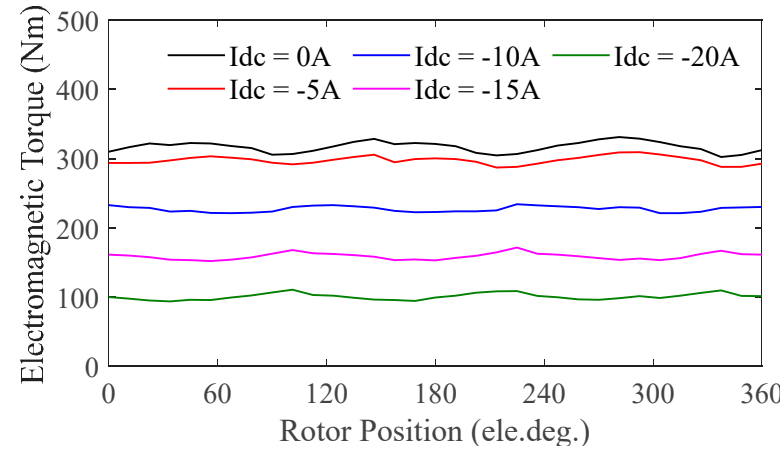

(a)

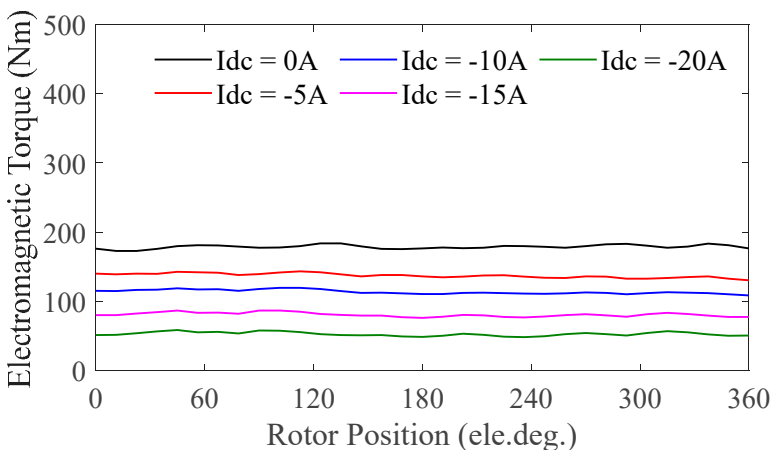

(c)

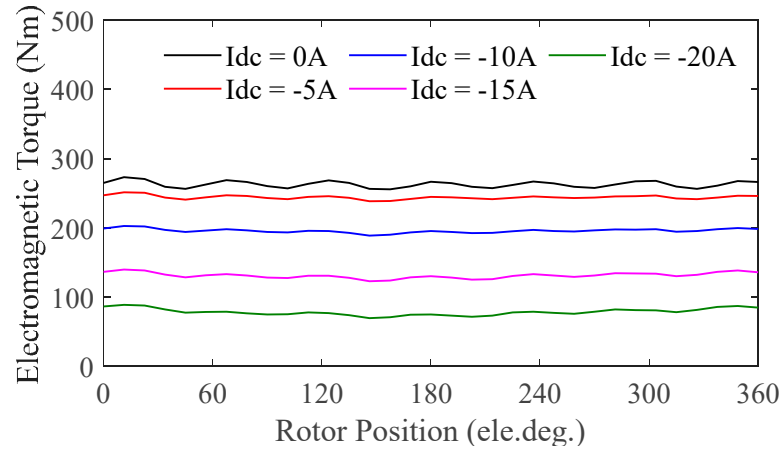

(b)

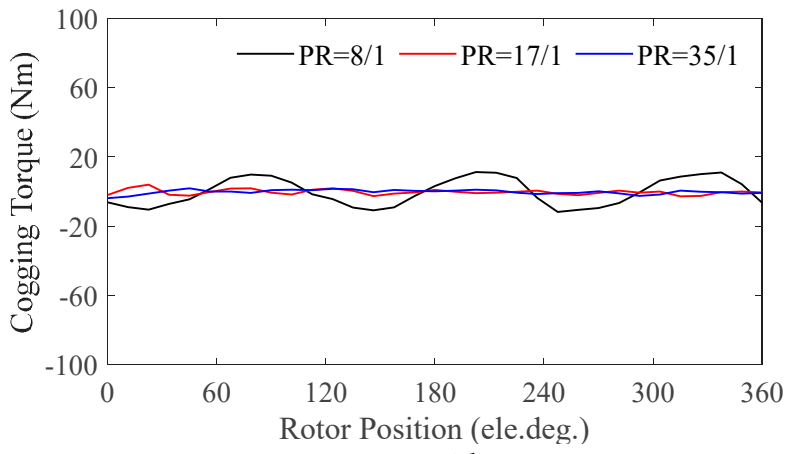

(d)

Figure 9. On-load electromagnetic torque and cogging torque waveforms of the proposed DRHAFPMVMs with different PRs. (a) On-load electromagnetic torque with PR of 8/1. (b) On-load electromagnetic torque with PR of 17/1. (c) On-load electromagnetic torque with PR of 35/1. (d) Cogging torque of three machines.

\subsection{Losses and Efficiencies}

The core losses of stator and rotor cores and the PM eddy current loss of three machines with the rated armature current under different DC excitation currents are calculated by 3-D FEM and compared in Figure 10. The core loss $p_{\text {iron }}$, including the hysteresis loss $p_{h}$, eddy current loss $p_{e c}$, and excess loss $p_{e}$, is expressed as follows

$$
p_{\text {iron }}=p_{h}+p_{e c}+p_{e}=k_{h} f B_{m}^{\alpha}+k_{e c} f^{2} B_{m}^{2}+k_{e} f^{1.5} B_{m}^{1.5}
$$

where $k_{h}$ is the hysteresis loss coefficient, $k_{e c}$ is the eddy current loss coefficient, and $k_{e}$ is the excess loss coefficient. The materials of the stator core and rotor core are both DW360-50, with $\alpha=2, k_{h}=168 \mathrm{w} / \mathrm{m}^{3}, k_{e c}=0.822 \mathrm{w} / \mathrm{m}^{3}$ and $k_{e}=0 \mathrm{w} / \mathrm{m}^{3} . B_{m}$ is the maximum flux density. $f$ is the electric frequency.

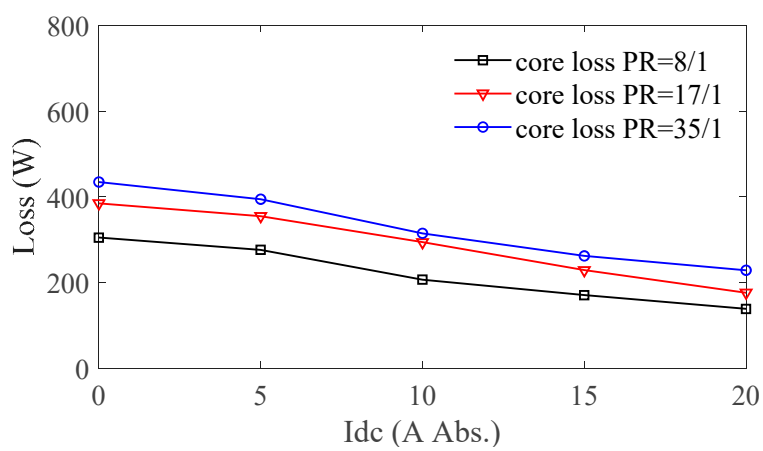

(a)

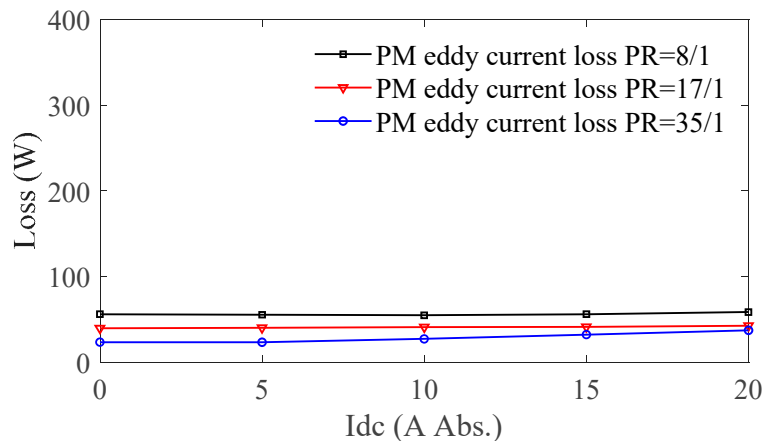

(b)

Figure 10. Evolution of losses as Idc under different PRs. (a) Core loss. (b) PM eddy current loss. 
It can be seen from Figure 10a that the total core loss decreases with the increase of the absolute value of DC excitation current due to the reduction of the average flux density of the stator main teeth from the short-circuiting effects. Additionally, the machine with higher number of rotor poles possesses higher frequency, resulting in more serious iron losses. Hence, the total core losses of three machines of PR 8/1, 17/1, and 35/1 without DC excitations are $305 \mathrm{~W}, 385 \mathrm{~W}$, and $434 \mathrm{~W}$, respectively.

Furthermore, the PMs are directly exposed to the armature reaction field, and, hence, the eddy current loss may be induced in the PMs. Despite the high-pole number of rotors, the fundamental frequency is low with a low-speed rotor, resulting in the PM eddy current losses not being prominent. Meanwhile, the DC excitation current has less effect on the potential harmonics of back-EMFs. The total PM eddy current losses are not sensitive to the variation of the DC excitation current, as shown in Figure 10b. The PM eddy current losses decrease with the increase in the number of rotor poles, namely, $56 \mathrm{~W}, 40 \mathrm{~W}$, and $23 \mathrm{~W}$, respectively. Additionally, the number of rotor poles also affects the area per PM pole exposed to air-gap. The larger the PR ratio, the lower the PM eddy current losses.

The copper losses are divided into the armature winding loss and the DC field winding loss, which follow Joule's law. Since the same geometric constraints of the stator cores are shared among the machines with different PRs, the coil lengths and the cross-sectional area of the armature windings and DC field windings are supposed to be the same. Hence, the copper losses are proportional to the square of the current, as shown in Figure 11, where Ia is the root mean square (RMS) value of the armature current. It can be seen from Figure $11 \mathrm{~b}$ that the copper loss caused by the DC excitation windings occupies a large proportion in the loss when the DC excitation current is relatively large. Deep flux-weakening leads to a reduction in machine efficiency and a temperature rise problem in the stator windings. Therefore, the range of flux-weakening is expected to be controlled under the condition of a long-term flux-weakening operation, while the range is expected to be wider under the condition of a short-term flux-weakening operation. The copper loss can be suppressed by the increase of the cross-sectional area of copper wire.

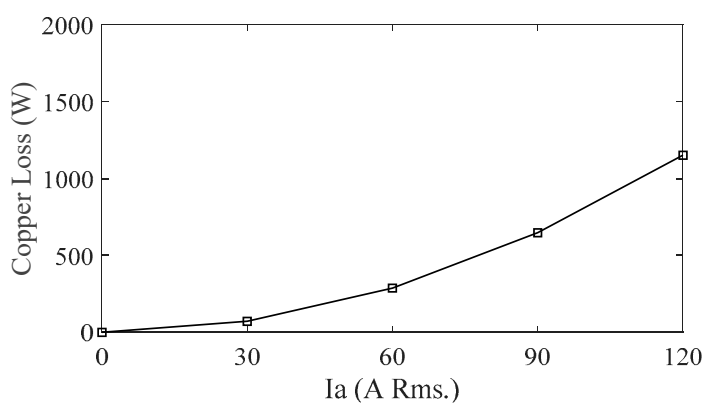

(a)

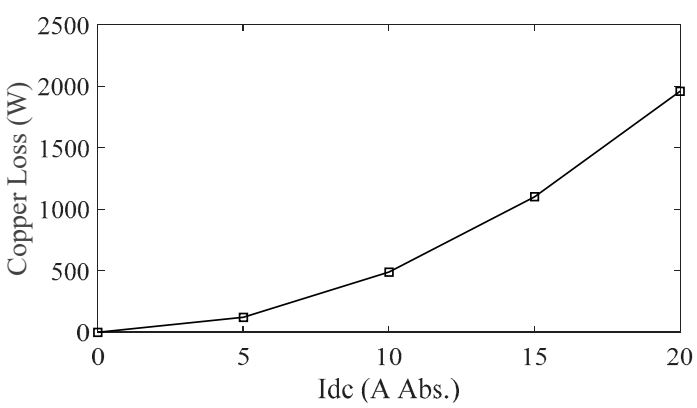

(b)

Figure 11. Evolution of copper losses as winding currents under different PRs. (a) The copper loss of armature windings. (b) The copper loss of DC field windings.

When mechanical loss and stray loss are not considered, the efficiency $\eta$ of the machines is calculated by

$$
\eta=\frac{P_{\text {out }}}{P_{\text {out }}+\sum p}=\frac{P_{\text {out }}}{P_{\text {out }}+P_{\text {iron }}+P_{\text {cu }}+P_{P M}}
$$

where $P_{\text {out }}$ is the output power, $P_{\mathcal{~} u}$ is the copper loss, and $P_{P M}$ is the PM eddy current loss.

The efficiency variation of the machines versus phase armature current and DC excitation current at rated speed is illustrated in Figure 12. Since the copper loss of DC field winding grows significantly with the increase of $I d c$, all the machines' efficiencies gradually decrease with increasing the flux-weakening depth. Thereinto, the machine with PR of $8 / 1$ holds the maximum efficiency throughout the flux-weakening stages compared 
with others, maintaining an efficiency over $75 \%$ within the absolute value of the DC field winding current of 15 amperes. The peak efficiency can reach $94 \%$ at rated armature current condition without DC excitations.

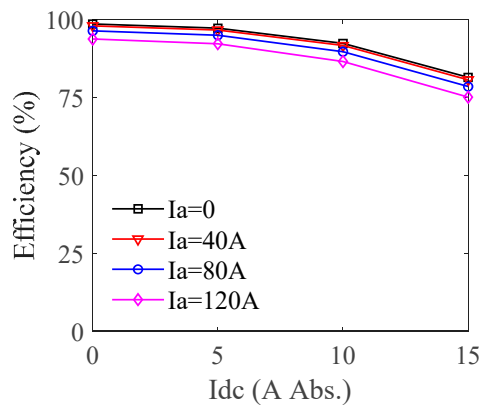

(a)

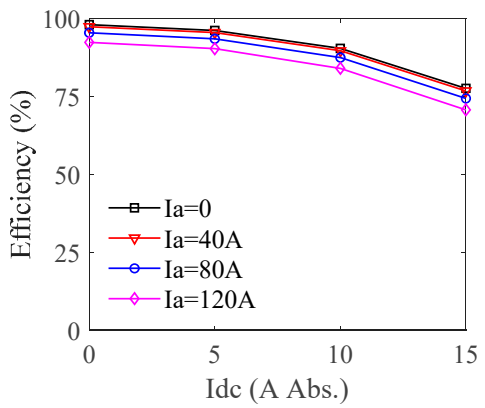

(b)

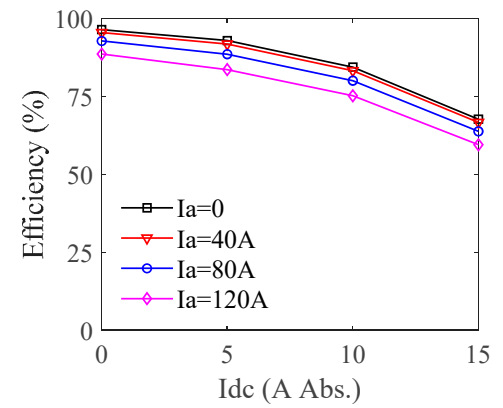

(c)

Figure 12. Evolution of efficiency as armature winding currents under different PRs at rated speed. (a) PR of $8 / 1$. (b) PR of $17 / 1$. (c) PR of 35/1.

\section{Conclusions}

In this paper, the dual-rotor modular-stator axial-flux permanent magnet vernier machine with hybrid excited windings is analyzed. Through the combination of the yokeless and segmented armature Torus NS configuration and the split-teeth of the stator cores, the air-gap flux densities are modulated to achieve high torque density at low speed. The DC excitation windings are embedded between split-teeth of the stator cores, which increases the space utilization ratio to enable flux regulation without decreasing torque capability. The flux modulation effect of the proposed machine is revealed by introducing the air-gap permeance function. The 3-D FEM based on the proposed machine model has been conducted to study the typical electromagnetic performances under different PRs and DC excitation currents. It has been found that the DC excitation winding wound between split-teeth of the stator cores can effectively weaken the amplitude of the armature phase flux linkage almost linearly by bypassing the main flux. By comparing the three PRs, it is concluded that the design with the PR of $8 / 1$ possesses higher torque density (up to $39.3 \mathrm{kNm} / \mathrm{m}^{3}$ ), higher machine efficiency (up to $94 \%$ ), and a significant flux-weakening ratio (up to $77 \%$ ) throughout the flux-weakening regions.

Author Contributions: All authors contributed to this work by cooperation. L.J., W.L. and A.Y. are the main authors of this manuscript and this work was conducted under the advisement of M.L. and K.L. All authors have read and agreed to the published version of the manuscript.

Funding: This work was supported in part by the State Key Program of National Natural Science Foundation of China under 51937002.

Institutional Review Board Statement: Not applicable.

Informed Consent Statement: Not applicable.

Data Availability Statement: Not applicable.

Conflicts of Interest: The authors declare no conflict of interest.

\section{References}

1. Toba, A.; Lipo, T.A. Generic torque-maximizing design methodology of surface permanent-magnet vernier machine. IEEE Trans. Ind. Appl. 2000, 36, 1539-1546.

2. Liu, C. Emerging Electric Machines and Drives-An Overview. IEEE Trans. Energy Convers. 2018, 33, 2270-2280. [CrossRef]

3. Zhu, Z.Q. Overview of novel magnetically geared machines with partitioned stators. IET Electr. Power Appl. 2018, 12, 595-604. [CrossRef]

4. Wu, F.; El-Refaie, M.A. Permanent magnet vernier machine: A review. IET Electr. Power Appl. 2019, 13, 127-137. [CrossRef]

5. Chen, Y.; Fu, W.N.; Ho, S.L.; Liu, H. A Quantitative Comparison Analysis of Radial-Flux, Transverse-Flux, and Axial-Flux Magnetic Gears. IEEE Trans. Magn. 2014, 50, 1-4. [CrossRef] 
6. Khatab, M.F.H.; Zhu, Z.Q.; Li, H.Y.; Liu, Y. Comparative Study of Novel Axial Flux Magnetically Geared and Conventional Axial Flux Permanent Magnet Machines. CES Trans. Electr. Mach. Syst. 2019, 2, 392-398. [CrossRef]

7. Atallah, K.; Howe, D. A novel high-performance magnetic gear. IEEE Trans. Magn. 2001, 37, 2844-2846. [CrossRef]

8. Qu, R.; Li, D.; Wang, J. Relationship between magnetic gears and vernier machines. In Proceedings of the 2011 International Conference on Electrical Machines and Systems (ICEMS), Beijing, China, 20-23 August 2011.

9. Xu, L.; Zhao, W.; Li, R.; Niu, S. Analysis of Rotor Losses in Permanent Magnet Vernier Machines. IEEE Trans. Ind. Electron. 2022, 69, 1224-1234. [CrossRef]

10. Song, Z.; Liu, C.; Zhao, H. Quantitative Comparison of Distinct Dual-Stator Permanent Magnet Vernier Machines for Direct-Drive Applications. IEEE Trans. Magn. 2019, 55, 1-6. [CrossRef]

11. Li, D.; Qu, R.; Lipo, T.A. High-Power-Factor Vernier Permanent-Magnet Machines. IEEE Trans. Ind. Appl. 2014, 50, 3664-3674. [CrossRef]

12. Niu, S.; Ho, S.L.; Fu, W.N. A Novel Stator and Rotor Dual PM Vernier Motor with Space Vector Pulse Width Modulation. IEEE Trans. Magn. 2014, 50, 805-808. [CrossRef]

13. Liu, W.; Lipo, T.A. Analysis of Consequent Pole Spoke Type Vernier Permanent Magnet Machine with Alternating Flux Barrier Design. IEEE Trans. Ind. Appl. 2018, 54, 5918-5929. [CrossRef]

14. Wei, F.R.; Zhu, Z.Q.; Qu, H. In analysis of novel dual-PM vernier machines. In Proceedings of the 2021 Sixteenth International Conference on Ecological Vehicles and Renewable Energies (EVER), Monte-Carlo, Monaco, 5-7 May 2021.

15. Hlioui, S.; Amara, Y.; Hoang, E.; Lecrivain, M.; Gabsi, M. Overview of hybrid excitation synchronous machines technology. In Proceedings of the 2013 International Conference on Electrical Engineering and Software Applications, Hammamet, Tunisia, 21-23 March 2013.

16. Oner, Y.; Zhu, Z.Q.; Chu, W. Comparative study of vernier and interior PM machines for automotive application. In Proceedings of the 2016 IEEE Vehicle Power and Propulsion Conference (VPPC), Hangzhou, China, 17-20 October 2016.

17. Li, W.; Ching, T.W.; Chau, K.T. A Hybrid-Excited Vernier Permanent Magnet Machine Using Homopolar Topology. IEEE Trans. Magn. 2017, 53, 1-7. [CrossRef]

18. Zhu, Z.Q.; Cai, S. Overview of hybrid excited machines for electric vehicles. In Proceedings of the 2019 Fourteenth International Conference on Ecological Vehicles and Renewable Energies (EVER), Monte-Carlo, Monaco, 8-10 May 2019.

19. Okada, K.; Niguchi, N.; Hirata, K. Analysis of a Vernier Motor with Concentrated Windings. IEEE Trans. Magn. 2013, 49, 2241-2244. [CrossRef]

20. Luo, X.; Niu, S.; Fu, W.N. Design and Sensorless Control of a Novel Axial-Flux Permanent Magnet Machine for In-Wheel Applications. IEEE Trans. Appl. Supercond. 2016, 26, 1-5. [CrossRef]

21. Giulii Capponi, F.; De Donato, G.; Caricchi, F. Recent Advances in Axial-Flux Permanent-Magnet Machine Technology. IEEE Trans. Ind. Appl. 2012, 48, 2190-2205. [CrossRef]

22. Taran, N.; Heins, G.; Rallabandi, V.; Patterson, D.; Ionel, D.M. Torque production capability of axial flux machines with single and double rotor configurations. In Proceedings of the 2018 IEEE Energy Conversion Congress and Exposition (ECCE), Portland, OR, USA, 23-27 September 2018.

23. Geng, W.; Zhang, Z.; Li, Q. High Torque Density Fractional-Slot Concentrated-Winding Axial-Flux Permanent-Magnet Machine with Modular SMC Stator. IEEE Trans. Ind. Appl. 2020, 56, 3691-3699.

24. Shao, L.; Navaratne, R.; Popescu, M.; Liu, G. Design and Construction of Axial-Flux Permanent Magnet Motors for Electric Propulsion Applications-A Review. IEEE Access 2021, 9, 158998-159017. [CrossRef]

25. Zou, T.; Li, D.; Qu, R.; Li, J.; Jiang, D. Analysis of a Dual-Rotor, Toroidal-Winding, Axial-Flux Vernier Permanent Magnet Machine. IEEE Trans. Ind. Appl. 2017, 53, 1920-1930. [CrossRef]

26. Allahyari, A.; Torkaman, H. A Novel High-Performance Consequent Pole Dual Rotor Permanent Magnet Vernier Machine. IEEE Trans. Energy Convers. 2020, 35, 1238-1246. [CrossRef]

27. Zhao, X.; Niu, S.; Fu, W. Design of a Novel Parallel-Hybrid-Excited Dual-PM Machine Based on Armature Harmonics Diversity for Electric Vehicle Propulsion. IEEE Trans. Ind. Electron. 2019, 66, 4209-4219. [CrossRef]

28. Mohamed, A.H.; Hemeida, A.; Vansompel, H.; Sergeant, P. Parametric Studies for Combined Convective and Conductive Heat Transfer for YASA Axial Flux Permanent Magnet Synchronous Machines. Energies 2018, 11, 2983. [CrossRef]

29. Zhu, Z.Q.; Howe, D. Instantaneous magnetic field distribution in brushless permanent magnet DC motors. III. Effect of stator slotting. IEEE Trans. Magn. 1993, 29, 143-151. [CrossRef] 